Revista Brasileira de Informática na Educação - RBIE Brazilian Journal of Computers in Education (ISSN online: 2317-6121; print: 1414-5685) http://br-ie.org/pub/index.php/rbie

$\begin{array}{llll}\text { Submission: 13/04/2020; } & 1^{\text {st }} \text { round notif.: 20/05/2020; } & \text { New version: 19/07/2020; } & 2^{\text {nd }} \text { round notif.: 14/09/2020; } \\ \text { Camera ready: 19/11/2020; } & \text { Edition review: 18/12/2020; } & \text { Available online: 20/12/2020; } & \text { Published: 20/12/2020; }\end{array}$

\title{
Eye tracking como estratégia educacional inclusiva: avaliação com estudantes com autismo
}

\author{
Title: Eye tracking as an inclusive educational strategy: assessment with students with autism
}

Tardelly de Araújo Cavalcante Universidade Federal do Piauí tardelly.cavalcante@ifpi.edu.br

Ivana Maia

Instituto Federal do Maranhão

ivana.maia@ifma.edu.br

\author{
Jordão Frazão Soares \\ Universidade Federal do Piauí \\ jordaofrazao@gmail.com \\ Priscila Benitez \\ Universidade Federal do ABC \\ priscila.benitez@ufabc.edu.br
}

\author{
Ancelmo Paiva \\ Universidade Federal do Maranhão \\ paiva@deinf.ufma.br \\ André Soares \\ Universidade Federal do Piauí \\ andre.soares@ufpi.edu.br
}

\begin{abstract}
Resumo
$\mathrm{Na}$ área de educação, profissionais ensinam e avaliam o repertório acadêmico de estudantes com as mais diversas habilidades, limitações e históricos. Alguns podem apresentar dificuldades de aprendizagem diante dos métodos convencionais de ensino, principalmente pela não adaptação aos métodos pedagógicos. Entre esses diversos estudantes, encontram-se os com Transtorno do Espectro Autista - TEA, os quais apresentam prejuízos na comunicação social e em padrões de comportamentos restritos e repetitivos. A análise do comportamento indica que atividades personalizadas, de acordo com os interesses dos estudantes, são mais eficientes no processo educacional. Este trabalho propõe usar a análise do rastreamento ocular (eye tracking) de estudantes durante a realização de atividades educacionais informatizadas, como estratégia de avaliação educacional inclusiva de estudantes com TEA. Para avaliação e demonstração dessa proposta, foram desenvolvidas atividades digitais de ensino no computador, as quais foram resolvidas por estudantes com diagnóstico de TEA. Os resultados dos experimentos evidenciam áreas das atividades que não foram olhadas pelos estudantes durante a resolução dessas atividades. Além disso, pode ser observado também se existe relação entre a movimentação do olhar e do cursor controlado pelo mouse durante a realização da atividade. Esta proposta também fornece meios para que o profissional, ao analisar o comportamento ocular do estudante, identifique se as atividades planejadas são eficientes em determinada fase do ensino. Dessa forma, a abordagem apresentada neste trabalho pode auxiliar o profissional educador na escolha de melhores metodologias de ensino, de acordo com o perfil de cada estudante.
\end{abstract}

Palavras-chave: Eye tracking, Educação Inclusiva, Transtorno do Espectro do Autismo, Análise do Comportamento Aplicada, $A B A$

\begin{abstract}
In the education field, professionals teach and evaluate students' academic repertoire with diverse skills, limitations, and backgrounds. Some of these students may have learning difficulties due to conventional teaching methods, mainly due to non-adaptation to pedagogical methods. Among these diverse students, there are those with Autistic Spectrum Disorder - ASD. Students with ASD present impairments in social communication and restricted and repetitive behavior patterns. Behavior Analysis indicates that activities tailored to the interests of students are more efficient in the educational process. This work proposes to use student eye-tracking analysis during computerized educational activities as a strategy for inclusive educational assessment of students with ASD. We developed digital teaching activities on the computer that were solved by students diagnosed with ASD to evaluate and demonstrate this proposal. The experimental results show areas of digital activities that do not receive student eye focus during these activities' execution. We may also observe if exists a relation between the eyes' movement and mouse-controlled cursor during the activity. It is essential to provide means for the professional to identify whether the activities proposed to students Cite as: Cavalcante, T.A., Soares, J.F., Paiva, A., Maia, I., Benitez, P., \& Soares, A.C.B. (2020). Eye tracking as an inclusive educational strategy: assessment with students with autism (Eye tracking como estratégia educacional inclusiva: avaliação com estudantes com autismo). Brazilian Journal of Computers in Education (Revista Brasileira de Informática na Educação-RBIE), 28, 1181-1204. DOI: 10.5753/RBIE.2020.28.0.1181.
\end{abstract}


are efficient at a given stage of the teaching. As well as find methodologies that fit the profile of each student. Moreover, eye tracking can assist in this process.

Keywords: Eye tracking, Inclusive Education, Autism Spectrum Disorder, Applied Behavior Analysis, ABA

\section{Introdução}

O Transtorno do Espectro Autista (TEA) é um transtorno do neurodesenvolvimento caracterizado por limitações relacionadas à interação social e comunicação, com padrões comportamentais restritos e interesses específicos (APA, 2013). O TEA manifesta-se de forma singular em cada criança, incluindo potencialidades e limitações. Como se trata de um espectro, os sintomas variam de leve, moderado até severo. A heterogeneidade dos sintomas ocasiona ampla variabilidade comportamental, o que significa que algumas pessoas com TEA podem, por exemplo, desenvolver uma fala fluente, enquanto outras serão não verbais ao longo de toda sua vida (Coderre et al., 2019).

Diante do quadro sintomatológico (APA, 2013), do aumento no número de pessoas diagnosticadas (Altenmüller-Lewis, 2017) e da prevalência do TEA (uma a cada 59 pessoas (CDC, 2001)), faz-se necessário refletir sobre os tratamentos eficazes, fundamentados em evidências. $\mathrm{Na}$ Análise do Comportamento Aplicada (ABA), uma intervenção é considerada eficaz, quando as estratégias comportamentais utilizadas produzem efeitos suficientes na modificação de comportamentos socialmente relevantes em função da comunidade verbal em que o estudante está inserido (Baer, Wolf, \& Risley, 1968; Cooper, Heron, Heward, et al., 2007). Evidências da eficácia da ABA são apresentadas na abundante literatura sobre o tema. Podemos observar mais de 1000 artigos científico sobre TEA publicados, os quais descrevem os sucessos da ABA (Foxx, 2008). Indivíduos de todas as idades são educados e tratados com sucesso há mais de 40 anos (Ferster, 1964), sendo que a ABA foi identificada como tratamento para indivíduos com autismo no início dos anos 1980 (DeMyer, Hingtgen, \& Jackson, 1981).

Os comportamentos específicos que se pretendem ensinar são definidos a partir de uma avaliação que envolve desde comportamentos mais elementares, como contato visual ao ser chamado pelo nome e seguimento de instrução, até aqueles mais sofisticados, como habilidades sociais (Higbee, 2012). Além de mensurar os desempenhos observáveis diretamente durante a aplicação do procedimento de ensino, como acertos e erros nas tarefas de avaliação e de ensino, podem ser utilizadas, de maneira complementar, medidas implícitas ao que se pretende avaliar e ensinar, tais como tempo e número de fixações do olhar para os estímulos, tempo gasto para movimentos sacádicos e rastreio ocular (Coderre et al., 2019). Avaliar a forma de processamento e rastreio visual dos estímulos apresentados em cada tarefa de avaliação e de ensino é importante para analisar o foco atencional e o desempenho individual de cada criança na realização de atividades que envolvem o ensino de diferentes comportamentos.

Segundo o artigo 27 da Lei no 13.146, Lei Brasileira de Inclusão da Pessoa com Deficiência (Estatuto da Pessoa com Deficiência) (BRASIL, 2015), a educação constitui direito da pessoa com deficiência, o qual deve ser assegurado por um sistema educacional inclusivo em todos os níveis, de forma que o indivíduo alcance o máximo desenvolvimento possível de seus 
talentos e habilidades físicas, sensoriais, intelectuais e sociais, segundo suas características, interesses e necessidades de aprendizagem. Há, entretanto, necessidades que interferem de maneira significativa no processo de aprendizagem e que exigem ações educativas específicas dos profissionais da área, como, por exemplo, a utilização de recursos e apoios especializados para garantir a aprendizagem de todos os alunos. Algumas dificuldades podem ser mais facilmente identificadas analisando-se o comportamento do olhar do aluno (com uso do eye tracking), que auxilia na definição de novas estratégias de ensino, sobretudo em relação às pessoas com TEA.

O uso de computadores e dispositivos eletrônicos nas pesquisas voltadas ao TEA expandese em ritmo acelerado (Shic \& Goodwin, 2015). Uma estratégia que tem sido comumente utilizada se refere ao eye tracking, um método não invasivo para realizar o rastreamento ocular e fornecer medidas que dificilmente seriam obtidas com uso de métodos tradicionais (Karatekin, 2007). O rastreamento ocular codifica informações sobre atenção, controle oculomotor e fatores psicológicos dos indivíduos (Duan et al., 2018) . O uso de eye tracking para captura e análise do comportamento ocular tem se intensificado nos últimos anos, principalmente no campo da Psicologia, com uso promissor no rastreio do processo cognitivo de aprendizagem (Lai et al., 2013).

Este trabalho tem o objetivo de demonstrar o uso do eye tracking para a avaliação do comportamento ocular de estudantes durante a resolução de atividades educacionais digitais, como estratégia de avaliação no ensino de comportamentos específicos complementares a alunos com TEA. Além disso, busca-se fornecer, através do eye tracking, medidas precisas do comportamento ocular dos estudantes durante a realização de tarefas no computador. Para demonstrar esta proposta, apresenta-se a análise de atividades digitais usando o eye tracking. Essas medidas são apresentadas em gráficos que potencializam as intervenções dos profissionais junto aos estudantes conforme suas necessidades específicas.

O profissional educador pode analisar esses gráficos, que viabilizam a identificação de variáveis críticas para o processo de ensino e aprendizagem, podendo, por meio da análise de dados, propor modificações no procedimento de ensino, com o propósito de garantir mais assertividade e personalização para cada estudante com TEA. Nesse contexto, foram desenvolvidas quatro atividades digitais para serem resolvidas pelos estudantes com aquisição das informações através de eye tracking. Os dados do rastreamento ocular podem ajudar a explorar a capacidade dos estudantes de categorizar eventos visuais e linguístico, bem como examinar objetos dinâmicos. Identificaram-se atividades em que o estudante errou e não olhou para os estímulos conforme o esperado, o que pode ter influenciado a resposta. Com isso, o profissional educador pode adaptar as estratégias das atividades, direcionando o ambiente digital para as reais necessidades específicas de cada estudante.

\section{Trabalhos Relacionados}

Nesta seção apresentamos trabalhos que investigam o uso de eye tracking na avaliação de aprendizagem e em temas relacionados às pessoas com TEA. 


\subsection{Eye Tracking e TEA}

O uso de computadores e dispositivos digitais tem sido apresentado como eficaz no ensino de pessoas com TEA (Silva, Moura, \& Soares, 2017). Aliado a isso, também tem sido utilizados sistemas de eye tracking em pesquisas com pessoas com TEA, por exemplo, no auxílio ao diagnóstico do TEA, como mostram as pesquisas de (Vargas-Cuentas et al., 2017), (Fujioka et al., 2016) e (Jiang \& Zhao, 2017).

Em (Chita-Tegmark, 2016) é apresentada uma revisão dos estudos de eye tracking que exploraram possíveis diferenças na atenção de indivíduos com e sem TEA para estímulos relacionados aos olhos, boca, rosto, corpo e elementos não sociais. O trabalho conclui que indivíduos com TEA alocam sua atenção de maneira diferente dos indivíduos sem TEA para diferentes estímulos. Isso evidencia que indivíduos com TEA distribuem sua atenção em diferentes partes de estímulos sociais (olhos, bocas, rostos, corpos) de maneira atípica e focam mais em estímulos não sociais.

O estudo de (Chawarska, Macari, \& Shic, 2013), mostrou que crianças com TEA atribuíam atenção fora do esperado a cenas sociais quando pistas didáticas foram introduzidas, mas não quando a cena não apresentava contato visual e fala. Verificou-se a preferência visual de crianças com TEA para áreas de imagens que não apresentam rostos humanos. O trabalho avaliou 65 crianças (34 com TEA e 31 sem TEA) exibindo imagens com os rostos humanos em diferentes áreas. Foi avaliado o tempo até a primeira fixação do olhar, duração total das fixações e média do número de visualização para cada estímulo, observando-se uma maior quantidade de fixações em áreas que não apresentavam o rosto humano (Almourad \& Bataineh, 2020).

O eye tracking também tem sido utilizado na avaliação de aprendizagem de pessoas com TEA. Em (Pereira Junior, de Menezes, \& De Souza, 2017) foi utilizado o rastreio ocular na avaliação da aprendizagem, a partir de jogos digitais. A avaliação foi realizada com os dados gerados pelo eye tracking de estudantes durante a execução de jogos digitais. (Almourad, Bataineh, Stocker, \& Marir, 2018), utilizaram os dados do eye tracking para analisar e comparar o comportamento de indivíduos com e sem TEA enquanto olhavam para diferentes estímulos, dentre eles o rosto humano. Nesse estudo, os autores observaram em crianças com TEA menos fixações nos olhos e mais na região da boca, comportamento diferente das crianças sem TEA. (Duan et al., 2018) coletaram, via eye tracking, dados de crianças com TEA para criar uma base de dados contendo os pontos em que indivíduos com TEA olharam em cada situação apresentada. (Moore et al., 2018) usaram eye tracking para verificar que um subgrupo de crianças com TEA, quando exposto a imagens sociais e geométricas, teve preferência por imagens geométricas. Já (Giordano et al., 2017), propuseram um sistema computacional integrado com o eye tracking que permite aos profissionais aplicarem testes, como o teste de deficit de atenção, utilizando rastreamento ocular.

(Busjahn et al., 2014) apresentam uma abordagem que busca ajudar a explicar como os novatos aprendem a ler e entender códigos de programação e a identificar melhorias no ensino e nas ferramentas de desenvolvimento. Com atividades preditivas de sacadas, descobriu-se que, à medida que as habilidades de vocabulário (e não a idade) aumentavam, crianças e adultos com Dificuldade Específica de Linguagem (DEL) são mais capazes de prever finais de frases apropriados, olhando mais cedo para a figura apropriada, entre opções disponíveis (Borovsky, Burns, Elman, \& Evans, 2013). 
O estudo de (Coderre et al., 2019) investigou se três medidas implícitas (movimento ocular, dilatação pupilar e potenciais eventos relacionados) poderiam estimar, de maneira consistente, o vocabulário receptivo (em tarefas de identificação) de cinco estudantes adultos com TEA severo (nível 3). O procedimento consistiu na apresentação de palavras conhecidas e desconhecidas, em tarefas compostas por figuras e palavras correspondentes. Após análise de sujeito único, os resultados mostraram que as medidas implícitas forneceram estimativas potenciais sobre o nível de vocabulário dos estudantes, concluindo que tais medidas podem ser úteis para avaliação das habilidades de linguagem do público-alvo investigado. Os autores recomendam ampliação da amostra e uso de medidas implícitas em situações de ensino, como preditivos para análise de comportamentos mais complexos, como a linguagem. O presente trabalho tem como objetivo analisar uma proposta de uso do eye tracking para auxiliar no planejamento e na avaliação de atividades educacionais inclusivas informatizadas.

O Quadro 1 apresenta um panorama dos trabalhos relacionados que utilizam o eye tracking na avaliação de aprendizagem. As colunas do Quadro apresentam os artigos, os tipos de eye tracker, os parâmetros monitorados (PM), utilização, tamanho do grupo (TG), idade, características estudadas (CE) e grupo (com e sem TEA).

No estudo de (Pereira Junior et al., 2017) foi avaliado o comportamento ocular de estudante em jogos digitais, mas não se incluíram estudantes com TEA. Em (Almourad et al., 2018), a avaliação feita compara o comportamento de estudantes com e sem TEA, considerando apenas as fixações e desconsiderando as sacadas. Em (Duan et al., 2018), é avaliada a atenção visual de estudantes com TEA, mas não se avaliam as sacadas. Por outro lado, (Moore et al., 2018), (Giordano et al., 2017) e (Busjahn et al., 2014) avaliaram estudantes da graduação sem TEA. (Borovsky et al., 2013) estudaram sacadas preditivas para avaliar vocabulário de estudantes sem TEA. (Coderre et al., 2019) estudaram estudantes com TEA com média de idade de 32 anos e não consideraram situação naturalística de sala de aula.

Consideraram-se, neste estudo, as seguintes características: utilização de eye tracking opensource, avaliação das medidas (Fixação, Sacadas, ScanPath e HeatMap), avaliação no ensino, idade escolar e experimentos com público de estudante com TEA. Além disso, associou-se a avaliação de atividades digitais realizadas por estudantes com TEA em um contexto educacional, utilizando-se soluções opensources. Observa-se que nenhum dos artigos apresenta todas as características apresentadas neste trabalho. 
Quadro 1: Caracterização dos trabalhos que utilizam eye tracking na avaliação de estudantes

\begin{tabular}{|c|c|c|c|c|c|c|c|}
\hline Trabalho & $\begin{array}{l}\text { Tipo de eye } \\
\text { tracker }\end{array}$ & PM & Utilização & TG & Idade & $\mathbf{C E}$ & Grupo \\
\hline $\begin{array}{l}\text { Busjahn } \\
\text { (2014) }\end{array}$ & $\begin{array}{l}\text { Dispositivo } \\
\text { Comercial - } \\
\text { CAM + IR }\end{array}$ & $\begin{array}{l}\text { Fixação e } \\
\text { Sacadas }\end{array}$ & $\begin{array}{l}\text { Avaliação } \\
\text { de Código } \\
\text { fonte }\end{array}$ & 2 & - & - & Sem \\
\hline $\begin{array}{l}\text { Vargas } \\
(2017)\end{array}$ & $\begin{array}{l}\text { Video feito } \\
\text { pro tablet }\end{array}$ & Iris & $\begin{array}{l}\text { Preferência } \\
\text { Visual }\end{array}$ & 31 & $2-6$ & $\begin{array}{l}\text { Preferência } \\
\text { Visual }\end{array}$ & Com/Sem \\
\hline $\begin{array}{l}\text { Fujioka } \\
\text { (2016) }\end{array}$ & $\begin{array}{l}\text { Dispositivo } \\
\text { Comercial - } \\
\text { CAM + IR }\end{array}$ & $\begin{array}{l}\text { Percentagem } \\
\text { de tempo } \\
\text { de fixação }\end{array}$ & Diagnóstico & 61 & $\begin{array}{l}15- \\
40\end{array}$ & - & Com/Sem \\
\hline Jiang (2017) & $\begin{array}{l}\text { Dispositivo } \\
\text { Comercial - } \\
\text { CAM + IR }\end{array}$ & $\begin{array}{l}\text { Movimento } \\
\text { Ocular }\end{array}$ & Diagnóstico & 39 & & $\begin{array}{l}\text { Preferência } \\
\text { Visual }\end{array}$ & Com/Sem \\
\hline $\begin{array}{l}\text { Pereira } \\
\text { Junior } \\
(2017)\end{array}$ & $\begin{array}{l}\text { CAM + } \\
\text { Software } \\
\text { Opensorces }\end{array}$ & Fixações & Jogos & 12 & - & - & Sem \\
\hline $\begin{array}{l}\text { Almourad } \\
\text { (2018) }\end{array}$ & $\begin{array}{l}\text { Dispositivo } \\
\text { Comercial - } \\
\text { CAM + IR }\end{array}$ & Fixações & $\begin{array}{l}\text { Avaliação } \\
\text { de imagens }\end{array}$ & 65 & $4-16$ & $\begin{array}{l}\text { Comparação } \\
\text { entre grupos, } \\
\text { Duração, } \quad 1^{\mathrm{a}} \\
\text { Última fixação }\end{array}$ & Com/Sem \\
\hline $\begin{array}{l}\text { Moore } \\
(2018)\end{array}$ & $\begin{array}{l}\text { Dispositivo } \\
\text { Comercial - } \\
\text { CAM + IR }\end{array}$ & $\begin{array}{l}\text { Fixações e } \\
\text { Sacadas }\end{array}$ & Avaliação & 227 & $1-2$ & $\begin{array}{l}\text { Tempo } \text { de } \\
\text { fixação visual } \\
\text { e o N } N^{\circ} \text { de } \\
\text { sacadas }\end{array}$ & Com/Sem \\
\hline Duan (2018) & $\begin{array}{l}\text { Dispositivo } \\
\text { Comercial - } \\
\text { CAM + IR }\end{array}$ & Fixações & Avaliação & 13 & $5-12$ & Atenção visual & Com \\
\hline $\begin{array}{l}\text { Giordano } \\
(2017)\end{array}$ & $\begin{array}{l}\text { Dispositivo } \\
\text { Comercial - } \\
\text { CAM + IR }\end{array}$ & $\begin{array}{l}\text { Fixações e } \\
\text { Sacadas }\end{array}$ & Avaliação & 22 & - & $\begin{array}{ll}\text { Atenção } & \text { e } \\
\text { distração }\end{array}$ & Com/Sem \\
\hline $\begin{array}{l}\text { Presente } \\
\text { Estudo }\end{array}$ & $\begin{array}{l}\text { CAM + } \\
\text { Software } \\
\text { Open } \\
\text { Sources }\end{array}$ & $\begin{array}{l}\text { Fixações, } \\
\text { Sacadas, } \\
\text { ScanPath e } \\
\text { HeatMap }\end{array}$ & $\begin{array}{l}\text { Avaliação } \\
\text { no Ensino }\end{array}$ & 7 & $8-12$ & $\begin{array}{ll}\text { Avaliação } & \text { de } \\
\text { atividades } & \\
\text { digitais } & \end{array}$ & Com \\
\hline
\end{tabular}

\section{Metodologia}

Este trabalho propõe o uso do eye tracking para fornecer medidas precisas do comportamento ocular dos estudantes durante a realização de tarefas no computador. Para demonstrar esta proposta, apresenta-se a análise de atividades digitais usando o eye tracking. Os dados são apresentados em gráficos que potencializam as intervenções dos profissionais junto aos estudantes conforme suas necessidades específicas. Nesse contexto, foram desenvolvidas quatro atividades 
digitais para serem resolvidas por cada estudante e, ao mesmo tempo, foi feita a aquisição das informações do comportamento ocular através do eye tracking.

As atividades foram desenvolvidas por psicóloga com experiência no ensino de estudantes com autismo. Foram escolhidas atividades de emparelhamento por identidade, ditado por composição com letras, composição de frase e identificação de frase. Os recursos visuais com imagens, palavras e frases são baseados em experiências anteriores da psicóloga. Os estudantes realizaram um procedimento de calibração, que consiste em olhar fixamente em pequenos círculos da cor azul, a uma distância de $50 \mathrm{~cm}$ a $80 \mathrm{~cm}$ entre a tela do computador e os olhos do estudante. Não foi limitado o tempo máximo para realização das atividades, ficando os estudantes livres para o uso do computador. Os dados do mouse e do rastreamento ocular foram salvos em arquivo no formato texto (txt) e para gerar os dados, usou-se a biblioteca MatPlotLib (Hunter, 2007).

Os dados do rastreamento ocular podem ajudar a explorar a capacidade dos estudantes de categorizar eventos visuais e linguísticos, bem como examinar objetos dinâmicos.

\subsection{Materiais}

Para os experimentos realizados no âmbito deste trabalho, utilizou-se um notebook com processador Intel i5, 4Gb (quatro gibabytes) de memória RAM, 256 Gb (duzentos e cinquenta e seis gibabytes) de HD, webcam Full HD integrada e monitor com resolução 1920x1080 pixel integrado. Para o rastreamento ocular, foi utilizada a biblioteca opensource PyGaze (Dalmaijer, Mathôt, \& Van der Stigchel, 2014). No desenvolvimento das atividades, foi utilizada a Engine de desenvolvimento Unity3D (Menard, 2011). No processamento gráfico dos resultados foi utilizada a biblioteca Matplotlib (Hunter, 2007).

\subsection{Participantes}

Foram selecionados 7 (sete) estudantes de uma escola municipal de ensino, 5 (cinco) do sexo masculino e 2 (duas) do sexo feminino, todos com alguma especificidade diagnosticada clinicamente por profissional, com base nos critérios do Diagnostic and Statistical Manual of Mental Disorders (APA, 2013). Os laudos médicos não apresentam o nível de severidade dos sintomas, assim como não foi aplicada uma escala para verificação de tais sintomas. Estudos futuros poderiam aplicar a Childhood Autism Rating Scale (CARS), ou "Escala de Pontuação para Autismo na Infância", que classifica os níveis do autismo segundo relato dos pais ou professores (Schopler, Reichler, DeVellis, \& Daly, 1980). Os 7 estudantes incluídos conseguiram realizar o procedimento de calibração exigidos pelo eye tracking. Todos os participantes tiveram os termos de consentimento assinados pelos respectivos responsáveis. 
Quadro 2: Caracterização dos participantes da pesquisa

\begin{tabular}{|l|l|l|c|l|ll|}
\hline Nome fictício & $\begin{array}{l}\text { Idade } \\
\text { cronológica }\end{array}$ & Tipo de escola & Sexo & $\begin{array}{l}\text { Atividades } \\
\text { realizadas }\end{array}$ & Diagnóstico \\
\hline Estudante 1 & 8 & Regular & $\mathrm{F}$ & $1,2,3$ e 4 & $\begin{array}{l}\text { TEA e deficiência } \\
\text { intelectual }\end{array}$ \\
\hline Estudante 2 & 12 & Especial & $\mathrm{M}$ & $1,2,3$ e 4 & TEA & \\
\hline Estudante 3 & 9 & Regular & $\mathrm{F}$ & $1,2,3$ e 4 & TEA & \\
\hline Estudante 4 & 11 & Regular & $\mathrm{M}$ & $1,2,3$ e 4 & $\begin{array}{l}\text { TEA e deficiência } \\
\text { intelectual }\end{array}$ \\
\hline Estudante 5 & 11 & Regular & $\mathrm{M}$ & $1,2,3$ e 4 & $\begin{array}{l}\text { TEA e transtorno do } \\
\text { déficit de atenção }\end{array}$ \\
\hline Estudante 6 & 10 & Regular & $\mathrm{M}$ & $1,2,3$ e 4 & TEA \\
\hline Estudante 7 & 13 & Especial & $\mathrm{M}$ & 1 e 2 & TEA \\
\hline
\end{tabular}

\section{Procedimento}

É importante garantir medidas implícitas durante o processo de ensino e aprendizagem de comportamentos específicos (Coderre et al., 2019) e o uso exaustivo de tais medidas em processos avaliativos com estudantes brasileiros. Os estudos de (Mercadante, Van der Gaag, \& Schwartzman, 2006; Orsati, Mecca, de Melo, Schwartzman, \& de Macedo, 2009; Orsati, Schwartzman, Brunoni, Mecca, \& de Macedo, 2008; Schwartzman, Velloso, D’Antino, \& Santos, 2015) evidenciam a relevância de medir com precisão os aspectos relacionados ao comportamento ocular a fim de identificar variáveis críticas durante a realização da tarefa, como fixação para os estímulos corretos e incorretos da tarefa antes de selecioná-los, se a criança está sob controle dos estímulos distratores e, com isso, replanejar as tarefas de ensino de maneira mais personalizada, visando à aprendizagem individual de cada um.

Os participantes descritos no Quadro 2 conseguiram realizar o procedimento de calibração exigidos pelo software eye tracking PyGaze. Cada participante se sentou em frente ao computador a uma distância de aproximadamente $50 \mathrm{~cm}$, olhando frontalmente para a tela do computador. O processo de calibração do eye tracking consiste em olhar fixamente para pequenos círculos posicionados em determinada região da tela do computador com fundo preto (Salvucci \& Goldberg, 2000).

Em seguida, as atividades em forma digital foram apresentadas sequencialmente para cada estudante. Durante a execução das atividades foram captados os dados do olhar de cada participante em forma de coordenadas $(\mathrm{x}, \mathrm{y})$ através de uma câmera e processamento de imagem (PyGaze). Após esse processo de execução das atividades, as informações do rastreio ocular de cada participante foram processadas individualmente com uso das bibliotecas Pygaze (Dalmaijer et al., 2014) e Matplotlib (Hunter, 2007) do Python. Esses dados foram utilizados para identificação de informações como fixações, sacadas e interações relacionais entre o eye tracking e o mouse. 


\subsection{Situação experimental}

Os experimentos foram realizados durante o atendimento educacional especializado (AEE), no contraturno ao período escolar em que os estudantes estavam matriculados. O professor do AEE acompanhou todo o processo de aplicação das atividades, junto ao pesquisador. A aplicação foi individualizada com cada estudante com TEA, de modo a garantir a situação naturalística de ensino prevista no AEE. É fundamental ressaltar que o formato de oferta do serviço do AEE varia de acordo com o município ou o estado. No caso do presente estudo, o AEE é oferecido individualmente para cada estudante, no contraturno escolar.

\subsection{Procedimento: seleção e aplicação das atividades com as crianças com TEA}

Inicialmente, foi realizado um processo de calibração, no qual os participantes ficaram sentados em frente ao computador a uma distância de aproximadamente $50 \mathrm{~cm}$, olhando frontalmente para a tela. O processo de calibração do eye tracking consiste em olhar fixamente para pequenos círculos posicionados em determinada região da tela do computador.

As atividades escolhidas são típicas do cotidiano escolar e envolveram quatro tipos. A Figura 1a refere-se a uma atividade mais elementar (A1), que consistiu no emparelhamento por identidade, em que cada criança era instruída a sobrepor a figura (parte inferior da tela) correspondente à sombra (parte superior da tela). A Figura $1 \mathrm{~b}$ representa uma atividade de ditado por composição, com uso de letras (A2), em que o estudante era instruído a escrever o nome da figura apresentada na tela, a partir da seleção das letras correspondentes disponíveis na parte inferior da tela. Nessas duas atividades, tanto as letras como os animais foram apresentados de maneira randomizada, com o intuito de diminuir o responder por posição.

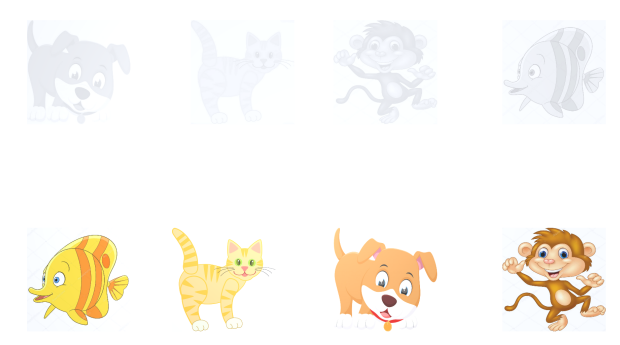

(a) Emparelhamento por identidade

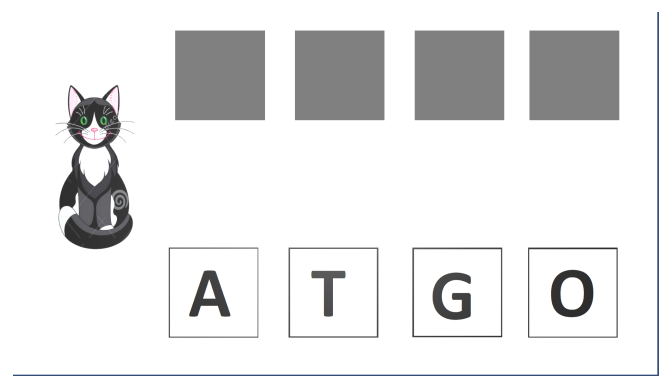

(b) Ditado por composição com letras

Figura 1: Exemplos das atividades que envolveram emparelhamento por identidade e ditado por composição com letras.

A Figura 2 ilustra as atividades mais complexas em relação às anteriores. A Figura 2a ilustra a atividade (A3), em que foi apresentada uma figura correspondente a uma ação, sendo a criança instruída a construir a frase a partir da seleção das palavras correspondentes, disponibilizadas na parte inferior da tela. A Figura 2 b exemplifica a atividade de identificação de frase (A4), na qual foi apresentada uma frase completa e quatro figuras no campo inferior da tela. Assim, a criança era instruída a ler a frase e a identificar a figura com a ação correspondente à frase.

Vale ressaltar que, ao movimentar um componente das atividades para o destino errado, 


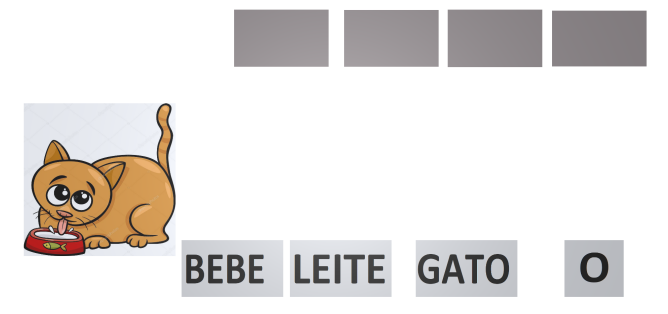

(a) Composição de frase

\section{O GATO BEBE LEITE}
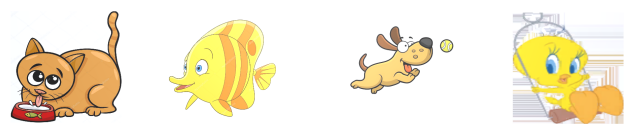

(b) Identificação de figuras

Figura 2: Exemplos das atividades para composição de frase e identificação de figuras a partir da frase impressa.

o objeto volta para o local original. Assim, o estudante somente consegue movimentar definitivamente cada componente das atividades se for para o local de destino correto. Em seguida, as atividades em forma de jogos digitais foram apresentadas sequencialmente para cada estudante individualmente. Durante a execução das atividades, foram rastreados os dados do olhar de cada participante em forma de coordenadas $(\mathrm{x}, \mathrm{y})$, a partir de câmeras e processamento de imagem, como informado na subseção 3.1.

\subsection{Análise dos dados}

Após o processo de execução das atividades, foram processadas as informações do rastreio ocular de cada participante individualmente, com uso das bibliotecas Pygaze (Dalmaijer et al., 2014) e Matplotlib do Python (Hunter, 2007). Esses dados foram utilizados para identificação de informações como fixações, sacadas e interações relacionais entre o eye tracking e o mouse, além da relação com o desempenho de acerto e erro para cada tarefa.

\section{Resultados e Discussões}

Os dados foram analisados e apresentados em duas categorias: uma geral, com as medidas analisadas, e outra específica, para cada criança com TEA.

\subsection{Análise geral dos dados}

A Figura 3 apresenta o mapa de calor referente a dois comportamentos oculares diferentes. O mapa de calor indica quais áreas da tela foram mais observadas pelo estudante. $\mathrm{O}$ aumento da intensidade de calor indica maior observação.

A partir da análise da Figura 3a, é possível afirmar que o estudante olhou para a figura do gato, apresentada na tarefa. Percebe-se pela Figura 3a que o estímulo planejado pelo profissional educador criou condições para que o Estudante 5 olhasse para o estímulo-alvo. Por outro lado, a Figura $3 \mathrm{~b}$ mostra, por meio do mapa de calor, que o Estudante 2 não olhou para a imagem do gato. Dessa forma, o profissional educador pode criar algumas hipóteses, como, por exemplo, a 


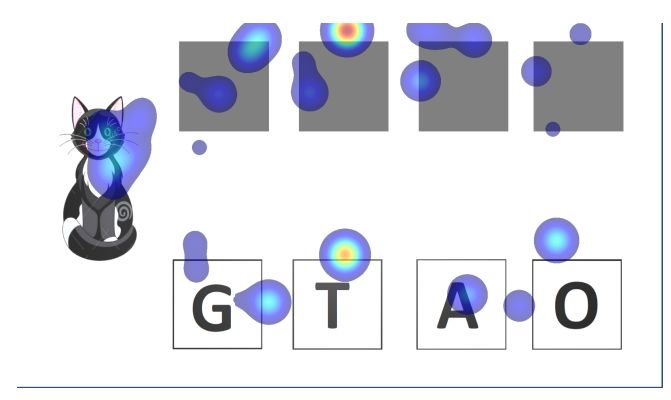

(a) Execução com foco no estímulo

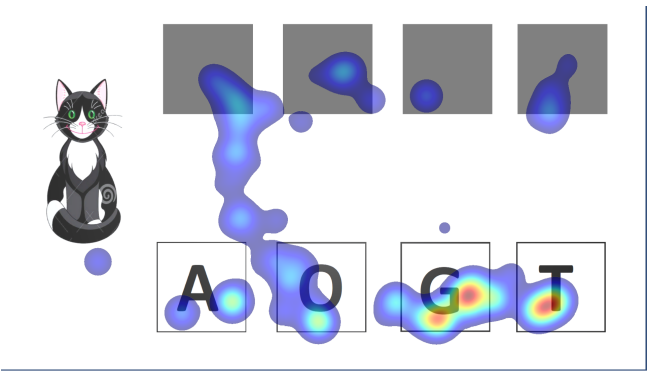

(b) Execução sem foco no estímulo

Figura 3: Mapa de calor do Estudante 5 (a) e do Estudante 2 (b).

de que a tarefa era muito fácil para o participante, sem a necessidade de ter que olhar para a figura do gato, ou a de que a tarefa não despertou o interesse do participante, ou ainda de que a atividade não está suficientemente adequada ao repertório do Estudante 2. Vale ressaltar que esse estudante pareceu demonstrar pouco interesse pela atividade, talvez porque o ambiente não apresentasse contingências reforçadoras suficientes para garantir o interesse na atividade.

A Figura 4 apresenta o movimento do olhar e do mouse durante a resolução da atividade A1 (formação da palavra gato), realizada pelo Estudante 5. Na parte superior da Figura 4, observa-se a movimentação do olhar (linha azul) e do mouse (linha laranja) para cada uma das 4 letras. Na parte inferior da Figura 4 (linha preta), apresenta-se o tempo de movimentação de cada uma das letras no processo de formação da palavra gato. Cada gráfico da parte inferior refere-se à movimentação de uma das letras. O eixo $\mathrm{X}$ representa o tempo decorrido durante toda a atividade. No eixo Y, o valor 1 (um) indica que a referida letra está selecionada pelo mouse, o que indica o processo de movimentação de cada uma das letras. $\mathrm{O}$ valor 0 (zero) indica que não houve movimentação da respectiva letra.
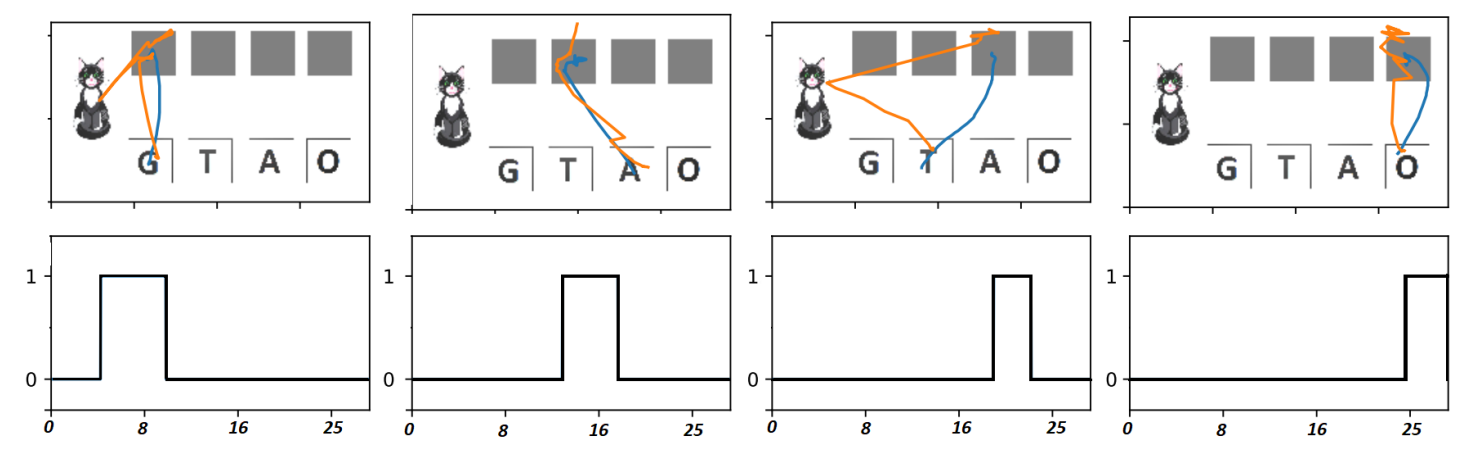

Figura 4: Execução segmentada da atividade de formar a palavra GATO pelo Estudante 5.

Ao analisar a Figura 4 o profissional educador sabe que o Estudante 5 movimentou primeiro a letra "G" e demorou cerca de 5 segundos para mover a letra "G" para o local correto. Em seguida o Estudante 5 moveu a letra "A", em 4 segundos. Depois o Estudante 5 moveu as letras "T" e "O", num tempo de, respectivamente, 3 e 4 segundos. A Figura 5 apresenta o mesmo tipo de gráfico da Figura 4, mas referente aos resultados do Estudante 2, que não olhou para a figura do gato. 

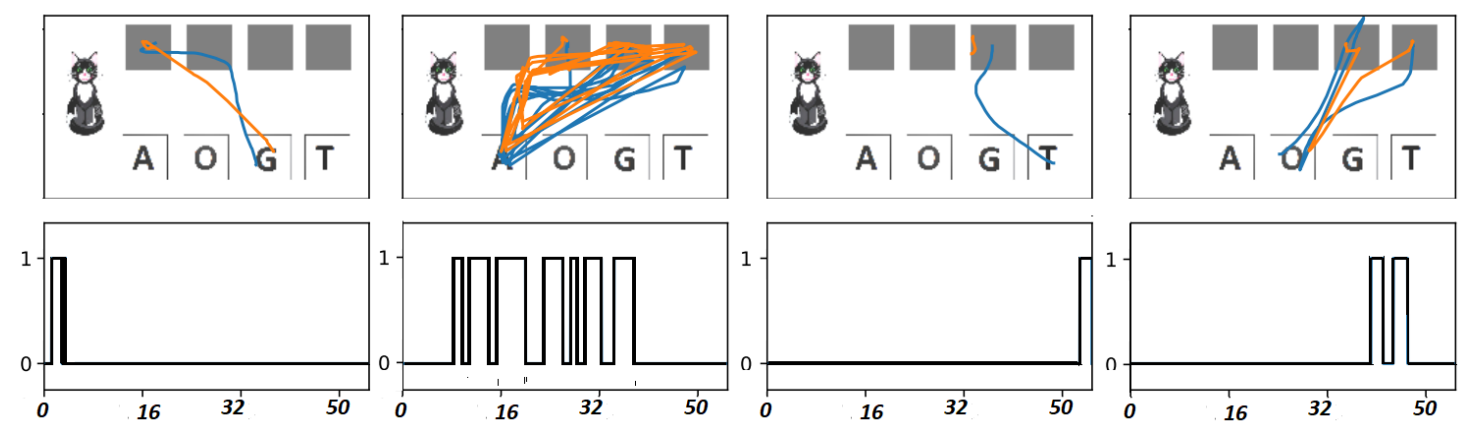

Figura 5: Execução segmentada sem foco no estímulo

Na Figura 5, ao analisar o tempo no qual cada letra foi movimentada, observa-se que o Estudante 2 movimentou inicialmente de forma correta a letra " $G$ " para a primeira posição da palavra, entretanto, observa-se também que a movimentação da letra "A" foi realizada várias vezes para todos os outros três espaços restantes. Isso sinaliza que o Estudante 2 movimentou a letra "A" aleatoriamente por sete vezes, até levá-la para o destino correto, a segunda posição. Em seguida o Estudante 2 passou a movimentar a letra "O" em duas tentativas, primeiro para a terceira posição e depois para a quarta posição. Por último, o Estudante 2 moveu a letra "T" corretamente em uma única tentativa para a terceira posição. É importante destacar que o Estudante 2 não olhou atentamente para a imagem do gato, conforme ilustrado na Figura 5. Vale ressaltar que foi observada correlação entre o movimento do mouse do computador e o movimento do rastreio ocular, relação apresentada pelas linhas azul para o mouse e laranja para o olhar nas Figuras 4 e 5. Essa correlação indica que o estudante movia o mouse e olhava a movimentação, comportamento esperado na resolução atenta de uma dada atividade no computador.

Outro dado importante são as fixações, que representam a manutenção do olhar (foco) em um determinado período de tempo em uma área da tela do computador. A Figura 6a apresenta as fixações e sacadas na resolução da atividade de emparelhamento com o modelo, realizada pelo Estudante 5. A Figura 6 b mostra as fixações e sacadas na resolução da atividade de formação de frase, feita pelo Estudante 3. Esse gráfico é formado por circunferências verdes que indicam a área dentro de determinado raio limite onde o estudante fixou o olhar durante um determinado período de tempo. Além das fixações, observam-se também as sacadas, representadas pelas ligações entre as fixações. A sacada é um movimento rápido entre duas fixações (Salvucci \& Goldberg, 2000). Ainda é possível analisar o trajeto entre as fixações indicando o caminho percorrido pelo olhar do estudante durante a realização da atividade.

A Figura 6a apresenta fixações bem alinhadas com os estímulos propostos na tarefa. Além disso, nota-se que os movimentos sacádicos foram correspondentes à movimentação entre as imagens e os seus respectivos destinos, indicando que a atividade foi bem entendida pelo estudante, uma vez que os movimentos dos olhos corresponderam ao que se espera durante a realização da atividade proposta.

A Figura 6b mostra um número maior de fixações e sacadas, se comparada com a Figura 6a. Isso já demonstra que a atividade de formação de frase é mais complexa em relação ao emparelhamento, conforme esperado. Essa informação pode demonstrar indícios de como e quais atividades serão as mais adequadas ao estudante. Esse tipo de análise pode ser útil para identificar 


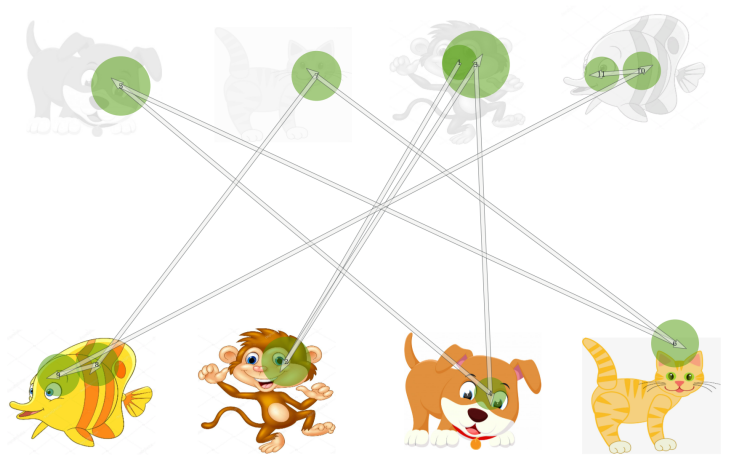

(a) Atividade realizada como esperado

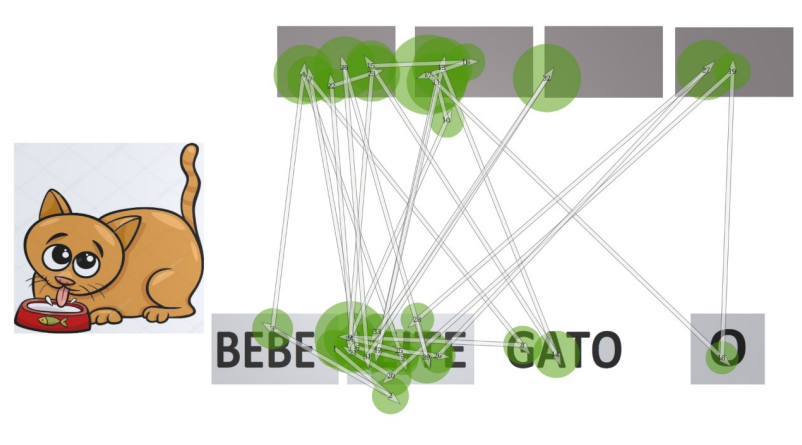

(b) Atividade realizada de maneira não esperada

Figura 6: Fixações e sacadas

que a atividade é complexa para o repertório do aluno e que não foi possível identificar o que deve ser feito na atividade.

De maneira geral, percebeu-se maior dificuldade na execução da tarefa de formação de frase, pois os estudantes levaram mais tempo para realizá-la. A Figura 7 mostra o comportamento do mouse do Estudante 6 na resolução da atividade de formação de frase.

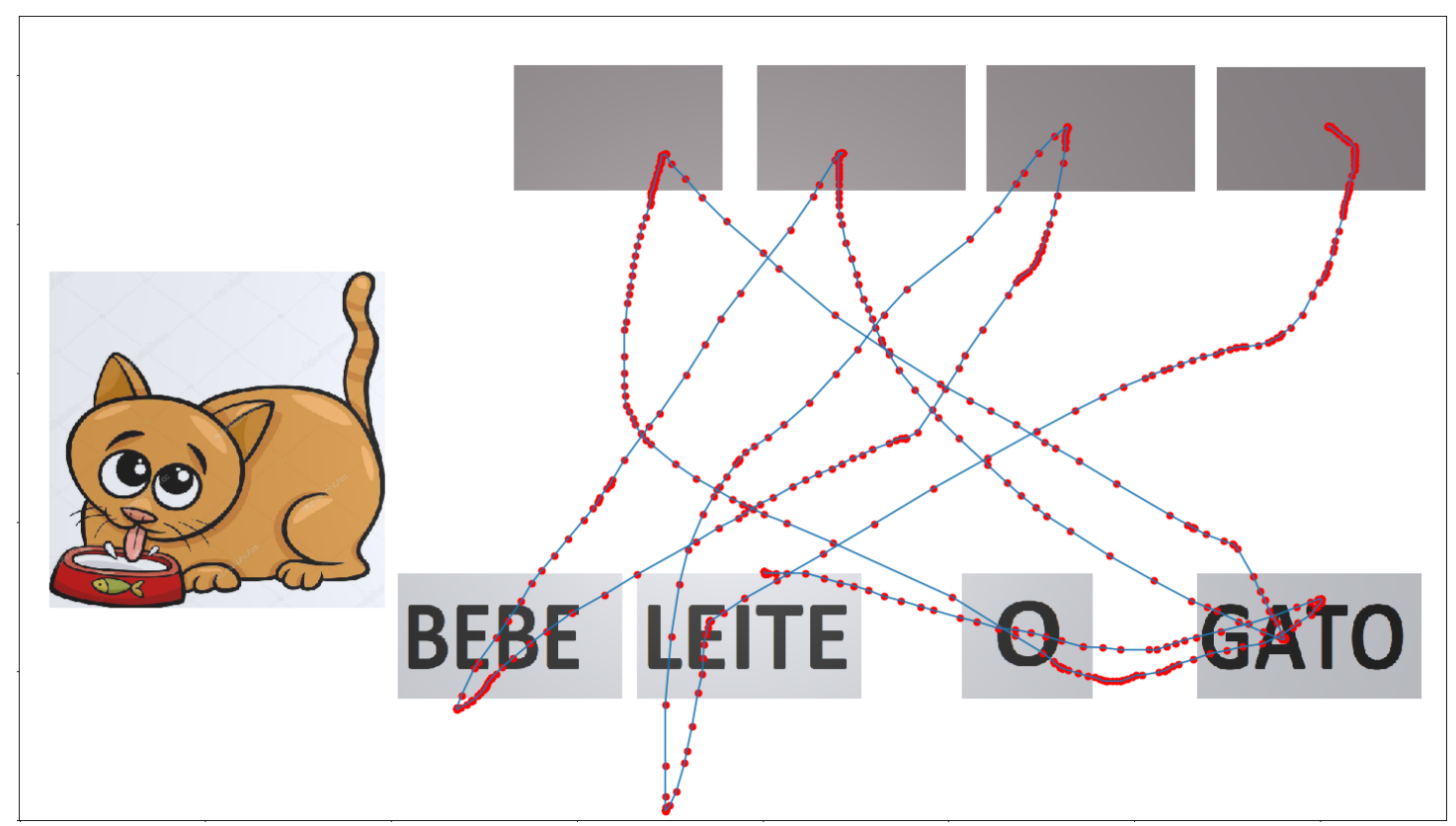

Figura 7: Movimentação do mouse

Os estudantes que demonstraram maior habilidade em resolver a atividade A3 apresentam na movimentação do mouse geralmente duas arestas em cada componente da atividade, como demonstrado na Figura 7. Tais informações sugerem que o estudante já possui repertório para resolver essa atividade e, assim, podem-se definir novas tarefas de maior desafio. 


\subsection{Análise do desempenho de cada criança com TEA}

Dados como a porcentagem do tempo em que o estudante mantém o olhar na tela também podem ser interessantes aos profissionais, pois é possível identificar a presença de distratores no ambiente ou outras limitações durante a resolução da atividade proposta. Os Estudantes 2, 3, 5 e 6 apresentaram mais de $92 \%$ do tempo com o olhar na tela, considerando todas as quatro atividades. O Estudante 1 apresentou 96,1\%;99,1\%;89,2\% e 51,6\% do tempo com olhar para a tela do computador, respectivamente para as atividades A1, A2, A3 e A4. O Estudante 4 apresentou $85,6 \% ; 99,9 \% ; 86,2 \%$ e $64,3 \%$ do tempo com olhar para a tela do computador, respectivamente para as atividades A1, A2, A3 e A4. O Estudante 7 somente resolveu as atividades A1 e A2, com respectivamente $36,3 \%$ e $93,9 \%$ do tempo com olhar para a tela do computador. É importante mencionar que o Estudante 7 estava assistindo a vídeos no celular da mãe antes de realizar a atividade proposta. Acredita-se que o baixo desempenho do Estudante 7 pode ter sido afetado pelo seu interesse em continuar assistindo ao vídeo no celular da mãe, em vez de realizar a tarefa proposta. De maneira geral, esses dados mostram que a maioria dos alunos passaram a maior parte do tempo olhando para a tela, sinalizando a efetividade da utilização do computador e do ambiente computacional na captação do interesse dos estudantes na atividade.

A Figura 8 relaciona o tempo necessário para resolução de cada atividade para cada estudante.

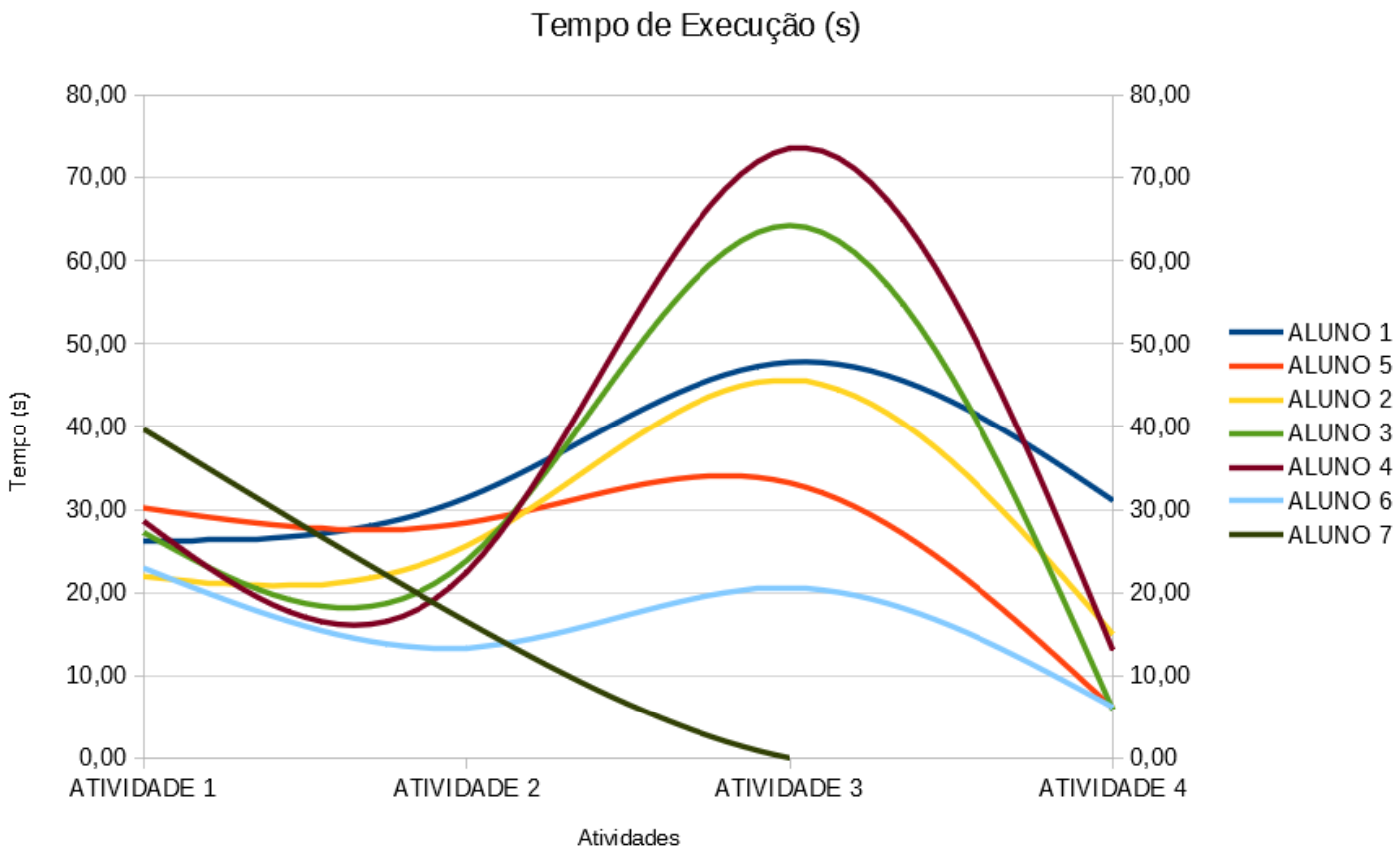

Figura 8: Relação do tempo de execução entre atividades de cada estudante.

De maneira geral, na Figura 8, nota-se que a relação do tempo gasto para a resolução de cada uma das atividades apresentou similaridade entre os estudantes. Isso foi observado apesar das especificidades de cada estudante e de seus diferentes repertórios. Percebe-se que a atividade A3 (formação de frase) foi a que demandou mais tempo dos estudantes, devido a sua maior 
complexidade.

O Estudante 7 não resolveu as atividades A3 e A4, respectivamente, de formação de frase e identificação de frase. A situação experimental não foi reforçadora o suficiente para garantir a realização do experimento com Estudante 7. Para tal, recomenda-se que aplicações futuras realizem avaliações de preferência e criem esquemas de reforço que favoreçam o engajamento do estudante na tarefa a ser realizada. Vale ressaltar que o Estudante 7 tem habitualmente muito contato com smartphones e dispositivos digitais, entretanto recusou-se a resolver as atividades A3 e A4 pré-estabelecidas como parte do experimento.

É importante destacar que o Estudante 7 resolveu apenas as atividades A1 e A2. Dada a situação de recusa para as demais atividades, optou-se pelo não prosseguimento. Acrescenta-se ainda que os outros estudantes apresentaram interesse e motivação na resolução das atividades propostas. Alguns, como 1, 2 e 4, sorriram ao acertar as questões e receber o estímulo reforçador de parabéns apresentado pelo computador ao final de cada atividade. Tais informações quantificadas pelo rastreio ocular e pelo movimento do mouse são medidas relevantes para o planejamento das atividades propostas pelo profissional educador.

Ainda relacionado à Figura 8, observa-se que os Estudantes 5 e 6 não apresentaram uma diferença significativa de tempo de resolução entre as atividades A1 e A3, as quais realizaram sem qualquer dificuldade. Acredita-se que a proximidade dos tempos das tarefas A1 e A3 está associada apenas à movimentação dos quatro componentes presentes nas duas atividades.

Detecta-se ainda que, no geral, houve um decréscimo de tempo de resolução significativo entre a atividade A3 e A4. Acredita-se que essa redução é justificada pela similaridade dos dados entre as atividades A3 e A4, as quais foram construídas com base na ação "o gato bebe leite". Tal comportamento sugere a aquisição do conhecimento no decorrer das resoluções de atividades anteriores.

Uma das professoras participantes do projeto relatou a importância desse tipo de trabalho, já que, ao programar sua atividade, estava considerando múltiplos elementos, no caso muitos estímulos para realização da mesma. Por exemplo, na Figura 6b, fica explícito que o aluno não rastreou a figura do gato bebendo o leite, indicando que o erro poderia ser evitado caso a atividade considerasse uma resposta de observação para o gato bebendo leite e posterior construção da frase. Garantir uma aprendizagem a pequenos passos e sem erros pode favorecer um ensino mais rápido, com maior acesso aos reforçadores (de Rose, 2005).

De maneira geral, os sete estudantes mostraram uma mesma tendência em relação a: i) tempo para realização da tarefa, ii) tempo de permanência do contato visual à tela durante a realização de cada tarefa e iii) o número de movimentações dos estímulos em cada tentativa apresentada por cada tarefa. Isso significa que, de maneira geral, os estudantes apresentaram maior tempo para realização da atividade, assim como maior tempo de fixação do comportamento ocular e maior número de movimentação dos estímulos para responder de maneira correta a atividade. As Figuras 9, 10 e 11 foram agrupadas conforme a proximidade do número de aplicações de cada atividade. Nessa parte do trabalho usa-se a sigla TT para representar as tentativas de responder cada atividade. 


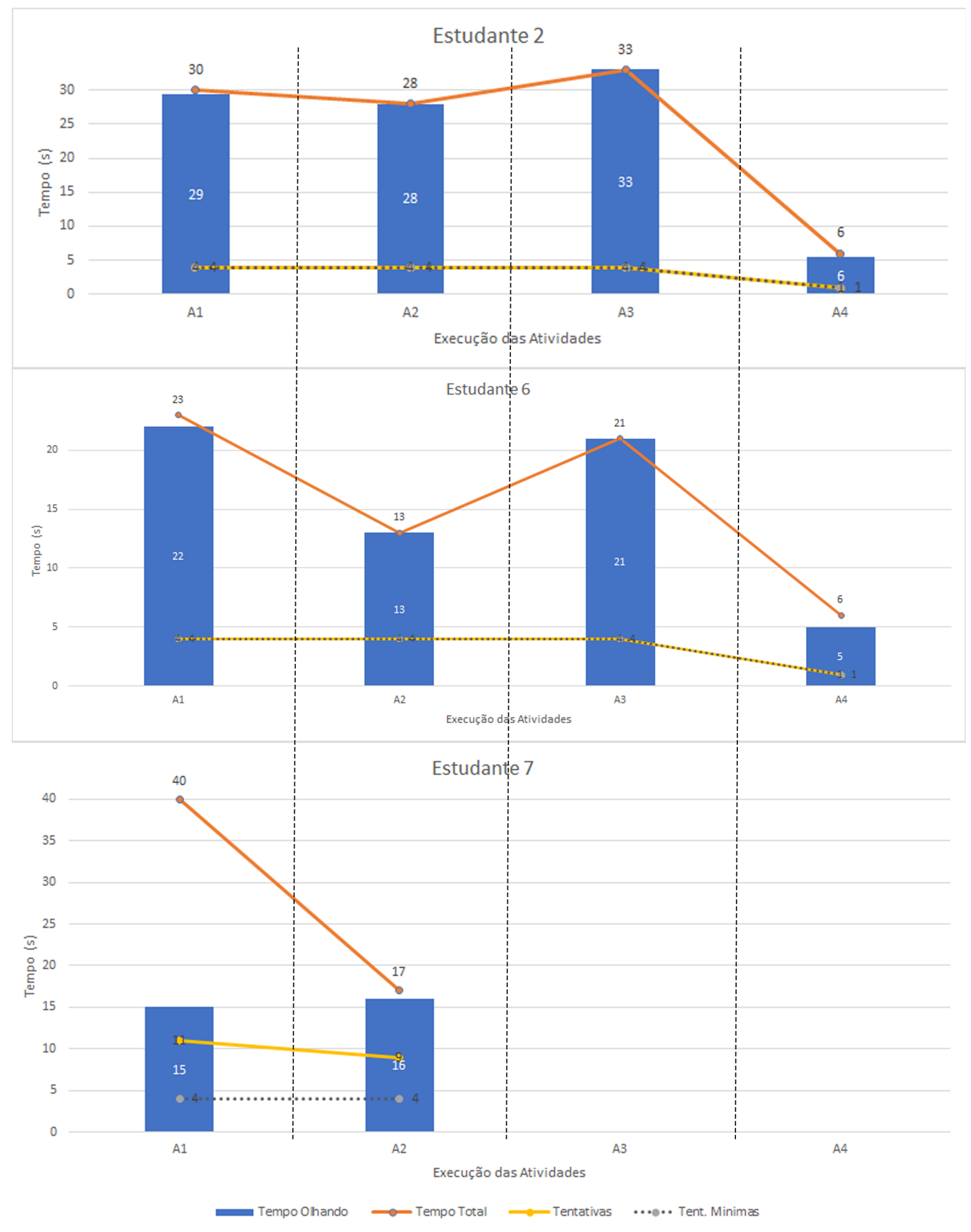

Figura 9: Desempenho do Estudante 2 ( $n=4$ aplicações), $6(n=4)$ e $7(n=2)$.

Na Figura 10, tanto o Estudante 3 como Estudante 4 aumentaram os tempos de contato visual para cada tentativa, em cada tarefa, em função do tempo total que demandaram para realizar cada atividade. Quando o estudante apresentou maior número de erros, o que significa que precisou 
movimentar maior número de vezes os estímulos apresentados, demandou maior tempo olhando para tela, assim como tempo total para completar a atividade, como pode ser exemplificado no caso do Estudante 3, na TT2 da A2 e TT1 da A3. Isso permite levantar a hipótese de que o estudante ainda não tinha compreendido a instrução da tarefa, respondendo com cliques incorretos à instrução apresentada.

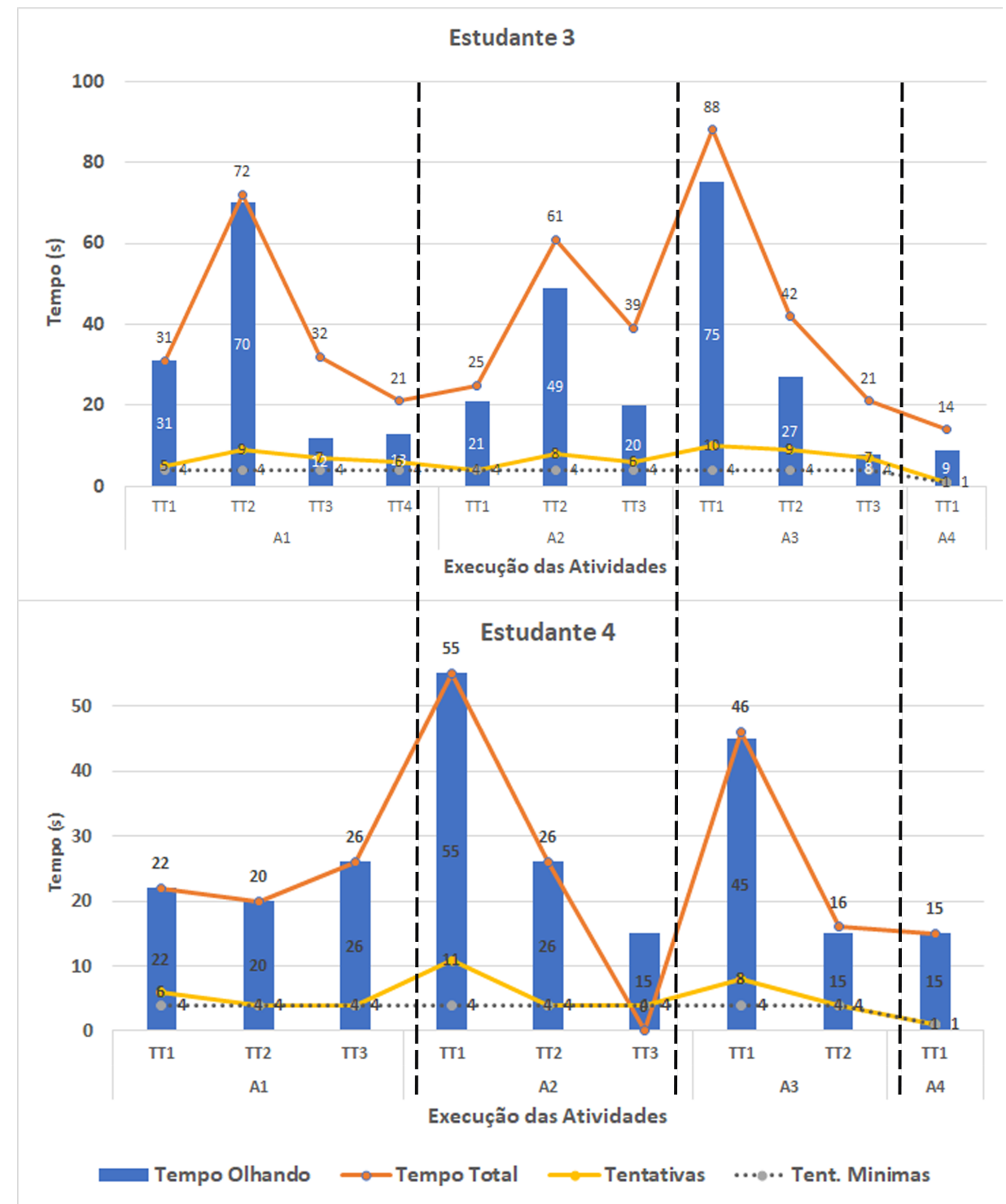

Figura 10: Desempenho do Estudantes 3 (n=11 aplicações) e Estudante 4 (n=9 aplicações).

Outro aspecto interessante que pode ser analisado com os dados do Estudante 3 (Figura 10), do Estudante 1 e do Estudante 5 (Figura 11) se refere ao maior tempo olhando para a tarefa com o tempo total para realização da tarefa na primeira vez em que cada atividade foi aplicada, em comparação a última tentativa. O Estudante 1, por exemplo, na A1, na TT1, olhou por 27 segundos e demorou o mesmo tempo para realização da tarefa, enquanto, na TT3 da mesma atividade, realizou a tarefa 19 segundos e olhou por 18 segundos. Os três apresentaram números maiores nas primeiras vezes que realizaram cada atividade e números menores nas últimas vezes, o que permite 
a hipótese do efeito de learning set, pois, mesmo sem a programação de critérios de aprendizagem, eles mostraram indícios ainda que incipientes de "aprender a aprender" (Catarina, 1999; Harlow, 1949; Saunders \& Spradlin, 1993) apenas com a exposição à tarefa e a consequência programada para acerto ao longo do procedimento.

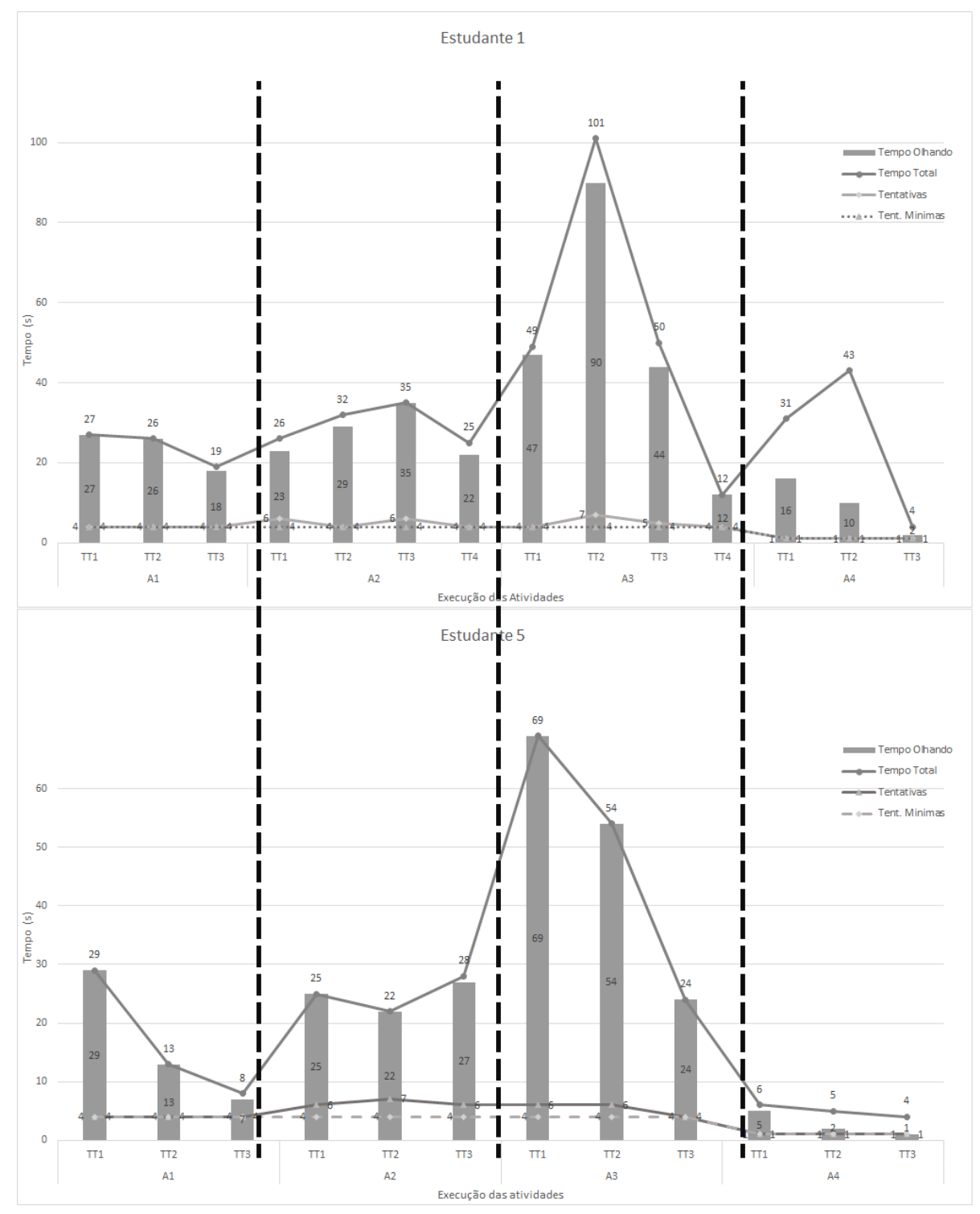

Figura 11: Desempenho de E1 ( $n=14$ aplicações) e E5 ( $n=12)$.

Ao analisar a Figura 8, observa-se que E6, com TEA e sem comorbidades, foi o estudante que demandou menor tempo de execução das atividades, entretanto tal análise isolada não permite afirmar que a ausência de comorbidades de E6 foi o fundamental para o seu melhor desempenho, sendo necessário um estudo mais aprofundado para investigar tais relações. Ao analisar a Figura 10, E4, com TEA e DI, obteve desempenho similar a E3, que apresentava apenas a condição TEA. Por fim, a Figura 11 mostra os resultados de E1 (TEA e DI) e E5 (TEA e TDAH), que apresentaram uma mesma tendência de desempenho. Assim, um estudo futuro deve ser realizado 
para investigar as questões relacionadas a comorbidades e aprendizagem.

Os dados sobre o desempenho dos estudantes apresentados nas Figuras 9, 10 e 11 também são apresentados no Quadro 3, em que cada atividade apresenta o tempo para realização da tarefa (TR), o tempo de permanência do contato visual à tela durante a realização de cada tarefa (TP), número de movimentações dos estímulos em cada tentativa apresentada por cada tarefa $(\mathrm{N})$ e status final da tarefa ST.

Quadro 3: Desempenho dos estudantes

\begin{tabular}{|c|c|c|c|c|c|c|c|c|c|c|c|c|c|c|c|c|c|}
\hline \multicolumn{18}{|c|}{ Atividades } \\
\hline & & \multicolumn{4}{|c|}{ A1 } & \multicolumn{4}{|c|}{ A2 } & \multicolumn{4}{|c|}{ A3 } & \multicolumn{4}{|c|}{ A4 } \\
\hline \multirow[t]{2}{*}{$\mathrm{E}$} & TT & TR & $\mathrm{TP}$ & $\mathrm{N}$ & ST & TR & $\mathrm{TP}$ & $\mathrm{N}$ & ST & TR & $\mathrm{TP}$ & $\mathrm{N}$ & ST & TR & $\mathrm{TP}$ & $\mathrm{N}$ & ST \\
\hline & 1 & 27 & 27 & 4 & FI & 26 & 23 & 6 & FF & 49 & 47 & 4 & FI & 31 & 16 & 1 & FI \\
\hline \multirow[t]{3}{*}{1} & 2 & 25 & 26 & 4 & FI & 32 & 29 & 4 & FI & 101 & 90 & 7 & FF & 43 & 10 & 1 & FI \\
\hline & 3 & 19 & 18 & 4 & FI & 35 & 35 & 6 & FF & 50 & 44 & 5 & FF & 4 & 2 & 1 & FI \\
\hline & 4 & - & - & - & $\mathrm{AB}$ & 25 & 22 & 4 & FI & 12 & 12 & 4 & FI & - & - & - & $\mathrm{AB}$ \\
\hline \multirow[t]{2}{*}{2} & 1 & 30 & 29 & 4 & FI & 28 & 28 & 4 & FI & 33 & 33 & 4 & $\mathrm{FF}$ & 6 & 6 & 1 & FI \\
\hline & 1 & 31 & 31 & 5 & FF & 25 & 21 & 4 & FI & 88 & 75 & 10 & FF & 14 & 9 & 1 & FI \\
\hline \multirow[t]{4}{*}{3} & 2 & 72 & 70 & 9 & $\mathrm{FF}$ & 61 & 49 & 8 & $\mathrm{FF}$ & 42 & 27 & 9 & FF & - & - & - & $\mathrm{AB}$ \\
\hline & 3 & 31 & 12 & 7 & FF & 39 & 20 & 6 & FF & 21 & 8 & 7 & $\mathrm{FF}$ & - & - & - & $\mathrm{AB}$ \\
\hline & 4 & 21 & 13 & 6 & FF & - & - & - & $\mathrm{AB}$ & - & - & - & $\mathrm{AB}$ & - & - & - & $\mathrm{AB}$ \\
\hline & 1 & 22 & 22 & 6 & FF & 55 & 55 & 11 & FF & 46 & 45 & 8 & $\mathrm{FF}$ & 15 & 15 & 1 & FI \\
\hline \multirow[t]{3}{*}{4} & 2 & 20 & 20 & 4 & FI & 26 & 26 & 4 & FI & 16 & 15 & 4 & FI & - & - & - & $\mathrm{AB}$ \\
\hline & 3 & 26 & 26 & 4 & FI & 15 & 15 & 4 & FI & - & - & - & $\mathrm{AB}$ & - & - & - & $\mathrm{AB}$ \\
\hline & 1 & 29 & 29 & 4 & FI & 25 & 25 & 6 & FF & 69 & 69 & 6 & $\mathrm{FF}$ & 6 & 5 & 1 & FI \\
\hline \multirow[t]{2}{*}{5} & 2 & 13 & 13 & 4 & FI & 22 & 22 & 7 & FF & 54 & 54 & 6 & FF & 5 & 2 & 1 & FI \\
\hline & 3 & 8 & 7 & 4 & FI & 28 & 27 & 6 & $\mathrm{FF}$ & 24 & 24 & 4 & FI & 4 & 1 & 1 & FI \\
\hline 6 & 1 & 23 & 22 & 4 & FI & 13 & 13 & 4 & FI & 21 & 21 & 4 & $\mathrm{FI}$ & 6 & 5 & 1 & $\mathrm{FI}$ \\
\hline 7 & 1 & 40 & 15 & 11 & $\mathrm{FF}$ & 17 & 16 & 9 & $\mathrm{FF}$ & - & - & - & $\mathrm{AB}$ & - & - & - & $\mathrm{AB}$ \\
\hline
\end{tabular}

O Quadro 3 apresenta as colunas TR e TP em segundos, N são as quantidades de tentativas realizadas e ST está classificada em finalizada (FI), finalizada com falha (FF) e abandonada (AB). Nesse quadro apresenta-se os dados do desempenho individual dos estudantes de forma ordenada.

\section{Conclusões}

Este trabalho apresentou a proposta de uso do eye tracking como estratégia para auxiliar na avaliação e planejamento de atividades de ensino no computador. Com isso o profissional educador passa a ter medidas precisas do comportamento ocular dos estudantes durante a realização de tarefas. Conforme discutido ao longo do trabalho, o comportamento ocular dos estudantes pode ser observado em gráficos que potencializam as intervenções dos profissionais junto aos estudantes conforme suas necessidades específicas. Além disso, a aplicação da pesquisa mostrou o uso do eye tracking em situação naturalística de ensino, por meio da aplicação durante 
o AEE, em situação escolar.

Essa proposta está em consonância com a Análise do Comportamento, que sugere a personalização das tarefas do indivíduo com base no seu desempenho e currículo, incrementando cada vez mais o seu aprendizado. Outro fator importante se refere ao feedback dado pelo profissional educador, após apresentação dos resultados das aplicações, no sentido de que tais análises puderam confirmar que os estudantes estavam olhando para o computador para realização das atividades, além de estarem sob controle das instruções e dos estímulos apresentados para a realização das tarefas, o que significa que eles estavam prestando atenção nas instruções dadas para emissão de cada resposta.

Discutiram-se também os casos de estudantes com TEA, que, em geral, apresentam maior número de erros em tarefas típicas de escrita e, nesse caso, esse tipo de análise poderia garantir uma atividade mais personalizada, visando ao acerto dos estudantes, como por exemplo, se ele fixa o olhar no lado direito, utilizar os estímulos corretos em tal posição e gradualmente modificálo de posição, garante-se maior número de respostas corretas. Ainda sobre o uso do eye tracking como ferramenta de ensino, no caso de estudantes com baixo contato visual, ao olhar para a tela, o estímulo apresentado começaria a piscar, visando ao aumento da manutenção do contato visual com a tela do computador, antes de apresentar a instrução da atividade. Tais estratégias podem, nesse sentido, auxiliar no planejamento de atividades que visem ao processo de aprendizagem dos estudantes supracitados.

A análise dos dados de desempenho dos estudantes permite entender o funcionamento do comportamento ocular durante a realização de tarefas típicas do cotidiano escolar de estudantes com TEA e ainda verificar que, apesar dos rótulos diagnósticos, seus desempenhos mudaram em função apenas da exposição à tarefa com uso de reforçamento diferencial, sem a programação de critérios de aprendizagem. Isso é fundamental para entender que tais estudantes, mesmo com rótulos de TEA com e sem deficiência intelectual (DI) são capazes de responder e mudar seus comportamentos em função de um procedimento personalizado para suas demandas. Assim, as mudanças do comportamento ocular ao longo da realização de tarefas podem ser consideradas, ainda que de maneira embrionária, um preditor do sucesso em atividades acadêmicas típicas do cotidiano escolar.

Uma das limitações do estudo realizado foi a não utilização de uma ferramenta ou técnica de avaliação do repertório individual de cada estudante antes dos experimentos. Tendo em vista isso, recomenda-se que em estudos futuros, seja realizada uma entrevista estruturada com os professores para garantir uma devolutiva mais sistemática que auxilie na programação de futuros trabalhos. Além disso, recomenda-se também a ampliação dos experimentos com um público maior.

Recomenda-se ainda que estudos futuros realizem um mesmo número de aplicações de cada atividade e relacione o repertório de entrada ao desempenho em cada atividade específica ao tempo de comportamento ocular. Sugere-se também que outras medidas implícitas sejam consideradas na análise, como o movimento sacádico e a dilatação da pupila, para entender se, com tais medidas, é possível também validar mudanças em função do processo de aprendizagem desse público-alvo.

Também como trabalhos futuros, pretende-se evoluir a proposta para incluir reforçadores imediatos e personalizados entre cada atividade, a fim de aumentar ainda mais o interesse dos estudantes. Além disso, pretende-se ampliar o experimento a outros públicos, incluindo estudantes 
com síndrome de Down e também em crianças sem transtorno ou deficiência, para verificar-lhes o desenvolvimento, de maneira a garantir o uso do eye tracking na perspectiva do desenho universal. Foram realizados testes iniciais com crianças com síndrome de Down e esquizofrenia e verificouse que a proposta pode ser considerada como estratégia educacional na sala de aula inclusiva, alcançando um grande público de estudantes, cujos ritmos de aprendizagem individuais devem ser respeitados.

Assim sendo, os dados avançam em relação à literatura prévia quanto ao uso exaustivo do eye tracking em procedimentos que visavam apenas a avaliação no contexto clínico e de diagnóstico, mostrando possibilidades de aplicação educacional e como ferramenta de ensino em atividades que envolveram o repertório de discriminação condicional.

\section{Referências}

Almourad, M. B., \& Bataineh, E. (2020). Visual attention toward human face recognizing for autism spectrum disorder and normal developing children: An eye tracking study. In Proceedings of the 2020 the 6th international conference on e-business and applications (p. 99-104). New York, NY, USA: Association for Computing Machinery. doi: 10.1145/3387263.3387283 [GS Search]

Almourad, M. B., Bataineh, E., Stocker, J., \& Marir, F. (2018). Analyzing the behavior of autistic and normal developing children using eye tracking data. In International conference on kansei engineering \& emotion research (pp. 340-349). doi: 10.1007/978-981-10-8612-0 6 [GS Search]

Altenmüller-Lewis, U. (2017). Designing schools for students on the spectrum. The Design Journal, 20(sup1), S2215-S2229. doi: 10.1080/14606925.2017.1352738 [GS Search]

APA, A. P. A. (2013). Diagnostic and statistical manual of mental disorders (dsm-5®). American Psychiatric Pub. [GS Search]

Baer, D. M., Wolf, M. M., \& Risley, T. R. (1968). Some current dimensions of applied behavior analysis 1. Journal of applied behavior analysis, 1(1), 91-97. doi: doi.org/10.1901/jaba.1968.1-91 [GS Search]

Borovsky, A., Burns, E., Elman, J. L., \& Evans, J. L. (2013). Lexical activation during sentence comprehension in adolescents with history of specific language impairment. Journal of Communication Disorders, 46(5), 413 - 427. doi: 10.1016/j.jcomdis.2013.09.001 [GS Search]

BRASIL (2015). Lei brasileira de inclusão da pessoa com deficiência. Retrieved from http:// www.planalto.gov.br/ccivil_03/_ato2015-2018/2015/lei/113146.htm [GS Search]

Busjahn, T., Schulte, C., Sharif, B., Simon, Begel, A., Hansen, M., ... Antropova, M. (2014). Eye tracking in computing education. In Proceedings of the tenth annual conference on international computing education research (p. 3-10). New York, NY, USA: Association for Computing Machinery. doi: 10.1145/2632320.2632344 [GS Search]

Catarina, A. (1999). Aprendizagem comportamento, linguagem e cognição.

CDC (2001). Prevalence of autism spectrum disorders. Centers for Disease Control and Prevention, Atlanta, USA. Retrieved from https://www.cdc.gov/ncbddd/autism/treatment .html [GS Search] 
Chawarska, K., Macari, S., \& Shic, F. (2013). Decreased spontaneous attention to social scenes in 6-month-old infants later diagnosed with autism spectrum disorders. Biological psychiatry, 74(3), 195-203. doi: 10.1016/j.biopsych.2012.11.022 [GS Search]

Chita-Tegmark, M. (2016). Attention allocation in asd: A review and meta-analysis of eyetracking studies. Review Journal of Autism and Developmental Disorders, 3(3), 209-223. doi: 10.1007/s40489-016-0077-x [GS Search]

Coderre, E. L., Chernenok, M., O’Grady, J., Bosley, L., Gordon, B., \& Ledoux, K. (2019). Implicit measures of receptive vocabulary knowledge in individuals with level 3 autism. Cognitive and Behavioral Neurology, 32(2), 95-119. doi: 10.10972FWNN.0000000000000194 [GS Search]

Cooper, J. O., Heron, T. E., Heward, W. L., et al. (2007). Applied behavior analysis. Retrieved from https://europepmc.org/backend/ptpmcrender.fcgi?accid=PMC1285958\&blobtype= pdf [GS Search]

Dalmaijer, E. S., Mathôt, S., \& Van der Stigchel, S. (2014). Pygaze: An open-source, crossplatform toolbox for minimal-effort programming of eyetracking experiments. Behavior research methods, 46(4), 913-921. doi: 10.3758/s13428-013-0422-2 [GS Search]

DeMyer, M. K., Hingtgen, J. N., \& Jackson, R. K. (1981). Infantile autism reviewed: A decade of research. Schizophrenia bulletin, 7(3), 388-451. doi: 10.1093/schbul/7.3.388 [GS Search]

de Rose, J. C. (2005). Análise comportamental da aprendizagem de leitura e escrita. Revista Brasileira de análise do Comportamento, 1(1), 29-50. doi: 10.18542/rebac.v1i1.676 [GS Search]

Duan, H., Zhai, G., Min, X., Fang, Y., Che, Z., Yang, X., ... Liu, N. (2018). Learning to predict where the children with asd look. In 2018 25th ieee international conference on image processing (icip) (pp. 704-708). doi: 10.1109/ICIP.2018.8451338 [GS Search]

Ferster, C. B. (1964). Positive reinforcement and behavioral deficits of autistic children. In Conditioning techniques in clinical practice and research (pp. 255-274). Springer. doi: 10.1007/978-3-662-39876-023 [GS Search]

Foxx, R. M. (2008). The critical importance of science-based treatments for autism. Association for Behavior Analysis Internationa's Newsletter, 30(3), 18-19. doi: 10.1016/j.chc.2008.06.007 [GS Search]

Fujioka, T., Inohara, K., Okamoto, Y., Masuya, Y., Ishitobi, M., Saito, D. N., ... others (2016). Gazefinder as a clinical supplementary tool for discriminating between autism spectrum disorder and typical development in male adolescents and adults. Molecular autism, 7(1), 19. doi: 10.1186/s13229-016-0083-y [GS Search]

Giordano, D., Pino, C., Kavasidis, I., Spampinato, C., Di Pietro, M., Rizzo, R., .. Barone, R. (2017). An eye tracker based computer system to support oculomotor and attention deficit investigations. In 2017 ieee 30th international symposium on computer-based medical systems (cbms) (pp. 538-543). doi: 10.1109/CBMS.2017.175 [GS Search]

Harlow, H. F. (1949). The formation of learning sets. Psychological review, 56(1), 51. doi: 10.1037/h0062474 [GS Search]

Higbee, T. S. (2012). The assert curriculum. unpublished manuscript. Unpublished manuscript, Department of Special Education and Rehabilitation, Utah State University, Logan, Utah, USA. [GS Search]

Hunter, J. D. (2007). Matplotlib: A 2d graphics environment. Computing in Science \& Engineering, 9(3), 90-95. doi: 10.1109/MCSE.2007.55 [GS Search] 
Jiang, M., \& Zhao, Q. (2017). Learning visual attention to identify people with autism spectrum disorder. In Proceedings of the ieee international conference on computer vision (pp. 32673276). doi: 10.1109/ICCV.2017.354 [GS Search]

Karatekin, C. (2007). Eye tracking studies of normative and atypical development. Developmental review, 27(3), 283-348. doi: 10.1016/j.dr.2007.06.006 [GS Search]

Lai, M.-L., Tsai, M.-J., Yang, F.-Y., Hsu, C.-Y., Liu, T.-C., Lee, S. W.-Y., ... Tsai, C.-C. (2013). A review of using eye-tracking technology in exploring learning from 2000 to 2012. Educational research review, 10, 90-115. doi: 10.1016/j.edurev.2013.10.001 [GS Search]

Menard, M. (2011). Game development with unity (1st ed.). Boston, MA, USA: Course Technology Press. [GS Search]

Mercadante, M. T., Van der Gaag, R. J., \& Schwartzman, J. S. (2006). Transtornos invasivos do desenvolvimento não-autísticos: síndrome de rett, transtorno desintegrativo da infância e transtornos invasivos do desenvolvimento sem outra especificação. Brazilian Journal of Psychiatry, 28, s12-s20. doi: 10.1590/S1516-44462006000500003 [GS Search]

Moore, A., Wozniak, M., Yousef, A., Barnes, C. C., Cha, D., Courchesne, E., \& Pierce, K. (2018). The geometric preference subtype in asd: identifying a consistent, early-emerging phenomenon through eye tracking. Molecular autism, 9(1), 19. doi: 10.1186/s13229-0180202-z [GS Search]

Orsati, F. T., Mecca, T. P., de Melo, D. F., Schwartzman, J. S., \& de Macedo, E. C. (2009). Padrões perceptuais nos transtornos globais do desenvolvimento: rastreamento ocular em figuras sociais e não sociais. Psicologia: teoria e prática, 11(3), 131-142. [GS Search]

Orsati, F. T., Schwartzman, J. S., Brunoni, D., Mecca, T., \& de Macedo, E. C. (2008). Novas possibilidades na avaliação neuropsicológica dos transtornos invasivos do desenvolvimento: Análise dos movimentos oculares. Avaliaçao Psicologica: Interamerican Journal of Psychological Assessment, 7(3), 281-290. [GS Search]

Pereira Junior, H., de Menezes, C., \& De Souza, A. (2017). Monitoramento dos movimentos dos olhos para apoiar a avaliação da aprendizagem em jogos digitais. In Brazilian symposium on computers in education (simpósio brasileiro de informática na educação-sbie) (Vol. 28, p. 787). doi: 10.5753/cbie.sbie.2019.1221 [GS Search]

Salvucci, D. D., \& Goldberg, J. H. (2000). Identifying fixations and saccades in eye-tracking protocols. In Proceedings of the 2000 symposium on eye tracking research \& applications (pp. 71-78). doi: 10.1145/355017.355028 [GS Search]

Saunders, K. J., \& Spradlin, J. E. (1993). Conditional discrimination in mentally retarded subjects: Programming acquisition and learning set. Journal of the Experimental Analysis of Behavior, 60(3), 571-585. doi: 10.1901/jeab.1993.60-571 [GS Search]

Schopler, E., Reichler, R. J., DeVellis, R. F., \& Daly, K. (1980). Toward objective classification of childhood autism: Childhood autism rating scale (cars). Journal of autism and developmental disorders. doi: 10.1007/BF02408436 [GS Search]

Schwartzman, J. S., Velloso, R. d. L., D’Antino, M. E. F., \& Santos, S. (2015). The eye-tracking of social stimuli in patients with rett syndrome and autism spectrum disorders: a pilot study. Arquivos de neuro-psiquiatria, 73(5), 402-407. doi: 10.1590/0004-282X20150033 [GS Search]

Shic, F., \& Goodwin, M. (2015). Introduction to technologies in the daily lives of individuals with autism. Springer. doi: 10.1007/s10803-015-2640-1 [GS Search] 
Silva, M., Moura, I., \& Soares, A. (2017). Uso de tecnologias computacionais para o ensino de crianças com transtorno do espectro autista: Um mapeamento sistemático da literatura. In Brazilian symposium on computers in education (simpósio brasileiro de informática na educação-sbie) (Vol. 28, p. 173). doi: 10.5753/cbie.sbie.2017.173 [GS Search]

Vargas-Cuentas, N. I., Roman-Gonzalez, A., Gilman, R. H., Barrientos, F., Ting, J., Hidalgo, D., ... Zimic, M. (2017). Developing an eye-tracking algorithm as a potential tool for early diagnosis of autism spectrum disorder in children. PloS one, 12(11). doi: 10.1371/journal.pone.0188826 [GS Search] 